\title{
O PAPEL DO TIROCÍNIO DOCÊNCIA NA FORMAÇÃO INICIAL DO MESTRE EM SAÚDE COLETIVA: UM RELATO DE EXPERIÊNCIA
}

\author{
THE ROLE OF THE TEACHING STAGE IN THE INITIAL TRAINING OF THE \\ MASTER IN COLLECTIVE HEALTH: A REPORT OF EXPERIENCE \\ Silas Santos Carvalho, Jéssica Santos Passos Costa, Laís Barbosa Souza Vilas Boas, Carlito \\ Lopes Nascimento Sobrinho
}

Universidade Estadual de Feira de Santana - UEFS

\begin{abstract}
The present essay aims to report an experience experienced by masters in the practice of teaching teaching, in the graduation of Dentistry, in the curricular component Biostatistics and Epidemiology. The shooting was carried out by three masters of the Graduate Program in Collective Health of the State University of Feira de Santana, for a class of the second semester of Dentistry and another. Under the supervision of a mentoring teacher. It was developed by reading the teaching plan of the curricular component; Organization of the proposed schedule of the same; Elaboration of lesson plans; Observation, presentation and presentation of theoretical and practical practices; And elaboration and correction of the activities stories. The experience of the pedagogical practice allows the sharing and exchange of knowledge between the students, masters and the teacher of the discipline, which contributes to the learning, improvement and overcoming of challenges of the teaching-learning process. Teaching methodology The teaching approach therefore plays a very important role in the postgraduate training, being considered indispensable in the process, since it is through this activity, general knowledge, consolidation in practice, helping to overcome possible difficulties related to the teaching practice, Collaborating significantly for the formation of a quality higher education teacher.
\end{abstract}

Key words: Internship, Collective Health, Teacher Training

\section{Resumo}

O presente ensaio tem como objetivo relatar a experiência vivenciada por mestrandos na prática do tirocínio docência, na graduação de Odontologia, no componente curricular Bioestatística e Epidemiologia. O tirocínio foi realizado por três mestrandos do Programa de Pós-Graduação em Saúde Coletiva da Universidade Estadual de Feira de Santana, para uma turma do segundo semestre do curso de Odontologia, da referida instituição, sob a supervisão de um professor orientador. Foi desenvolvido mediante leitura do plano de ensino do componente curricular; organização da proposta de cronograma do mesmo; elaboração de planos de aula; observação, participação $e$ apresentação das aulas teóricas e práticas; $e$ elaboração e correção das atividades avaliativas. A experiência da prática pedagógica possibilitou o compartilhamento e a troca de conhecimentos entre os alunos, mestrandos e o professor da disciplina, que contribuíram para o aprendizado, aperfeiçoamento e superação de desafios do processo de ensino-aprendizagem. O tirocínio docência assume, portanto, um papel de grande relevância na formação do pós-graduando, sendo considerado indispensável nesse processo, visto que, é através desta atividade que o conhecimento teórico se consolida na prática, auxiliando na superação de possíveis dificuldades relacionadas à prática docente, colaborando significativamente para a formação de um docente do ensino superior de qualidade.

Palavras chave: Ensino, Saúde Pública, Docente. 


\section{Introdução}

O tirocínio docência consiste em um estágio supervisionado, parte integrante da formação do pós-graduando na área docente, devendo ter acompanhamento de docente qualificado e experiente, sendo considerado indispensável, pois é nele onde o futuro docente universitário pode expor seu conhecimento e criatividade ${ }^{1}$.

O estágio implica em uma prática didática e pedagógica, a qual possibilita a articulação da relação ensino-aprendizagem e seus constantes desafios, não apenas a ligação técnica, mas também, uma reflexão crítica sobre esta prática e a realidade em que se processa ${ }^{2,3}$.

Nesse contexto, Freire 4:23 afirma que "quem forma se forma e re-forma ao formar, e quem é formado forma-se e forma ao ser formado". Dessa forma, há uma parceria de modo ativo no processo ensino-aprendizagem, no qual tanto o docente quanto 0 discente aprendem mutuamente $^{3}$. Para isso, o estágio supervisionado não requer simplesmente a utilização de procedimentos de ensino para a reprodução do conhecimento, a definição de objetivos de cunho ético, ideológico, filosófico e político, mas também, possibilitar ao professor ser um profissional reflexivo e criativo e um cidadão consciente e crítico, a fim de compartilhar valores, opiniões, crenças e práticas de interação e convivência ${ }^{3}$.

A formação do docente universitário em programas de pós-graduação stricto sensu é considerada de grande relevância, embora, seja evidente a insuficiência de iniciativas de maior valorização institucional e dos órgãos de fomento e avaliação quanto a esta prática ${ }^{5,6}$. Nesse contexto, Chamlian7 (p. 59) afirma que, "[...] mais do que uma formação pedagógica, em sentido estrito, a necessidade está no despertar da valorização da tarefa de ensino".

Dessa forma, por meio da Portaria n.o 76, de 14 de abril de 2010, a Coordenação de Aperfeiçoamento de Pessoal de Nível Superior $(\mathrm{CAPES})^{8}$, estabelece que o mestrando e doutorando realizem atividades de ensino sob a supervisão do docente orientador, sendo que estas devem estar em conformidade e harmonia com a área de pesquisa do programa de pósgraduação realizado pelo pós-graduando, de modo que uma não se sobreponha à outra.

O Programa de Pós-Graduação em Saúde Coletiva da Universidade Estadual de Feira de Santana (PPGSC/UEFS), conforme as orientações da CAPES, assume o compromisso com a formação de mestres que estejam aptos para o desenvolvimento de pesquisas no campo da saúde coletiva e que se apropriem de referenciais teórico-metodológicos, que fundamentem o exercício da docência no ensino superior. Assim, oferta na instituição o tirocínio docência, sob a supervisão de um professor orientador. Essa atividade, no mestrado, equivale a 30 horas semestrais, devendo ser realizado em um componente curricular da área de Saúde Coletiva, entre os ofertados pelos cursos do Departamento de Saúde da UEFS.

Diante da relevância do tirocínio docente para formação profissional, o presente ensaio tem como objetivo relatar a experiência vivenciada por mestrandos na prática do tirocínio docência na graduação de Odontologia, no componente curricular Bioestatística e Epidemiologia.

\section{Metodologia}

Este artigo trata de um relato de experiência, de caráter descritivo com abordagem qualitativa, sobre o tirocínio docência de três mestrandos do Programa de Pósgraduação em Saúde Coletiva da Universidade Estadual de Feira de Santana (UEFS), com distintas formações de graduação; Enfermagem, Educação física e Psicologia e dois desses mestrandos com experiência de docência no Ensino Fundamental e Médio. A experiência ocorreu no período de março a julho de 2017, semanalmente, em dia fixo, tendo como discentes 11 graduandos do segundo semestre do Curso de Odontologia, no componente curricular Bioestatística e Epidemiologia, do Departamento de Saúde da referida instituição, sob a supervisão do professor responsável por este componente curricular.

Tal componente curricular caracteriza-se com um modelo teórico-prático, com carga horária de 60 horas e tem como objetivos: reconhecer os usos e aplicações da Bioestatística no campo da pesquisa e na prática da saúde coletiva; utilizar técnicas de pesquisa epidemiológica; reconhecer os fundamentos científicos em que se baseia a Epidemiologia para - estudo do processo saúde-doença em populações humanas; calcular e analisar, criticamente, os principais indicadores de saúde na população; apresentar os Sistemas de Informação em Saúde e fontes de dados, discutindo sua utilização em Epidemiologia; distinguir os diferentes tipos de estudo epidemiológicos, suas principais aplicabilidades, bem como, as vantagens e desvantagens de cada 
tipo de estudo.

O tirocínio docência foi desenvolvido mediante leitura do plano de ensino do componente curricular; organização da proposta de cronograma do mesmo; elaboração de planos de aula; observação, participação e apresentação das aulas teóricas e práticas; e elaboração e correção das atividades avaliativas.

Os mestrandos elaboraram e apresentaram sete aulas teóricas sobre os seguintes temas: uma sobre Introdução à Bioestatística; uma sobre Indicadores de Morbidade; uma sobre Indicadores de Mortalidade; uma sobre Representação Gráfica e Tabular; três aulas sobre Desenhos de Estudos Epidemiológicos. Também elaboraram e ministraram uma aula prática sobre Representação Gráfica e Tabular. Ainda participaram de mais duas aulas, onde aplicaram duas provas de avaliação de conteúdo, que foram elaboradas pelos mesmos.

As aulas expositivas dos temas propostos na programação da disciplina foram realizadas pelos mestrandos com o auxílio de recurso audiovisual (data-show) e suportadas pelas bibliografias recomendadas a cada aula, para favorecer a preparação prévia dos alunos e sua participação em sala de aula.

Foram utilizados recursos complementares aos temas abordados nas aulas expositivas, como estudos dirigidos, correção e discussão de exercícios, demonstrações práticas em sala de aula, com o objetivo de, através de situações problemas, os alunos aplicarem os conhecimentos adquiridos nas aulas. Atividades lúdicas como paródias musicais, jogos de perguntas e respostas (quiz interativo), oficina de artigos e aula prática em laboratório. Essas atividades foram executadas com objetivo de revisão do conteúdo apresentado, buscando ampliar a apropriação dos conteúdos trabalhados pelos graduandos.

Um relatório foi construído com o intuito de descrever as atividades realizadas durante o período do tirocínio docência e as percepções dos mestrandos sobre o mesmo, tais como: as experiências vivenciadas e adquiridas em sala de aula com os discentes, e professor orientador do componente curricular e as estratégias utilizadas diante dos desafios enfrentados.

\section{Resultados e Discussões}

O tirocínio docência caracteriza-se pela participação do pós-graduando em atividades de ensino através do acompanhamento do professor no desenvolvimento de um componente curricular na instituição, objetivando a preparação para a docência, por meio da reflexão crítica da prática, bem como, da realidade onde esta se desenvolve. Assim, os três mestrandos participaram do planejamento das intervenções didáticas; da apresentação de aulas teóricas e práticas; e da elaboração, aplicação e correção das atividades avaliativas, o que lhes proporcionou uma visão ampla acerca da prática educativa.

Atualmente, nos programas de pósgraduação stricto sensu, nota-se uma preponderância do incentivo à pesquisa, em detrimento da prática do ensino ${ }^{6}$. Entretanto, Zaidan et al. ${ }^{9}$ chamam a atenção para o fato de que a formação nesses programas possui entre seus objetivos principais, além da formação de pesquisadores, também a qualificação profissional do exercício docente para ensino superior. $E$, nesse sentido, a vivência de inserção do profissional nesse campo de trabalho, analisando suas práticas, se torna de grande relevância para sua qualificação e formação.

Deste modo, primeiramente, foi realizada a leitura do plano de ensino do componente curricular, a fim de conhecer os objetivos, conteúdos, metodologias e referências bibliográficas a serem utilizadas e os modos de avaliações previstos. A partir daí, foi organizado o cronograma de atividades com o intuito de atingir os objetivos propostos para a disciplina. $\mathrm{O}$ plano de ensino é um documento elaborado pelo docente, constituído por sua proposta de trabalho, numa área e/ou disciplina específica. É considerado um instrumento facilitador, uma vez que orienta como será desenvolvido o trabalho docente no período letivo ${ }^{10}$. Nessa perspectiva, o contato com plano de ensino é parte fundamental para nortear e conduzir a prática docente.

Na sequência, houve o contato inicial com a turma, a partir da observação e participação nas aulas do professor responsável pela disciplina. Realizou-se a apresentação do professor e dos tirocinistas e, logo após, a dos alunos e suas expectativas em relação à disciplina. Ao longo dos encontros, foram realizadas discussões sobre as temáticas das aulas, envolvendo os alunos, os mestrandos e o professor do componente curricular.

De acordo com Freire ${ }^{11}$, uma das formas do professor aprender a ensinar é por meio da observação de aulas - a aprendizagem por observação. Este é um momento importante, pois permitiu aos pós-graduandos quebrar a 
tensão inicial diante do primeiro contato com alunos, possibilitou conhecer as características da turma e a exposição contínua gera uma familiaridade entre os sujeitos no contexto da sala de aula, diminuindo barreiras e resistências. Além disso, constituiu uma valiosa oportunidade de aprender estratégias (posturas) em sala de aula e também apreender técnicas e métodos de ensino.

Uma das funções primordiais do tirocínio docência é propiciar essa aproximação com a prática docente no ensino superior. $O$ estágio docente permite uma primeira aproximação com a prática profissional, promovendo a aquisição de um saber fazer e um saber julgar as consequências das ações didáticas e pedagógicas desenvolvidas no cotidiano profissional ${ }^{11}$. Joaquim, Vilas Boas e Carrieri ${ }^{12}$, em sua pesquisa com pós-graduandos matriculados no estágio docente, verificaram que o principal sentido de se desenvolver tal atividade está relacionado à aproximação com a prática em sala de aula, onde o contato direto com os alunos possibilita a vivência da relação professor-aluno sob outra perspectiva e auxilia na aquisição de segurança perante os alunos em sala de aula.

O passo seguinte foi a elaboração do plano de aula, o qual consiste na sistematização de todas as atividades que serão desenvolvidas no período de tempo em que o professor e o aluno irão interagir na dinâmica de ensinoaprendizagem $^{13}$. Para Fusari ${ }^{10}$, o preparo das aulas é uma das atividades mais importantes do trabalho do professor, por isso, nada deve substituir essa tarefa, pois, cada aula é um encontro, onde é tecida a rede do currículo escolar proposto para determinada faixa etária, modalidade ou grau de ensino.

Frente à relevância dessa atividade e influenciados pelas orientações do supervisor, que sempre enfatizou a necessidade do professor estabelecer uma conexão com o aluno, de modo a envolvê-lo no processo de aprendizagem, esse momento foi marcado pelas inquietações de quais estratégias metodológicas e recursos didáticos poderiam ser utilizados para melhor abordar o conteúdo e estimular a participação dos alunos, auxiliando-os na compreensão da temática.

A partir disso, na apresentação da primeira aula sobre "Introdução à Bioestatística" utilizouse a modalidade de aula expositiva, com o auxílio de recurso audiovisual (data-show). Com o intuito de atrair a atenção da turma, foram feitas demonstrações práticas das medidas de tendência central e dispersão. Durante a aula, também foram feitas perguntas a fim de estimular a participação dos alunos, buscando relacionar o conteúdo apresentado com as experiências adquiridas por eles no cotidiano. Paródias musicais foram utilizadas para ajudar na fixação de conceitos da Bioestatística de forma lúdica e descontraída. Ao final, foi entregue um estudo dirigido (para ser resolvido em casa) com situações problemas, para que os alunos pudessem aplicar o conhecimento adquirido na aula.

A aula é o momento em que se concretiza, efetiva e se constrói o processo de ensinar e aprender. Logo, deve ser concebida como um momento curricular importante, no qual o educador deve fazer a mediação competente e crítica entre os alunos e os conteúdos do ensino, buscando sempre direcionar a ação docente para estimular os alunos ao desenvolvimento da percepção crítica da realidade e de seus problemas e estimulá-los ao desenvolvimento de atitudes de tomada de posição frente aos conflitos da sociedade ${ }^{10}$. Além disso, para Freire $^{11}$, o desempenho na sala de aula - a ação instrucional - é mais uma forma do professor aprender a ensinar.

Após a apresentação desta primeira aula, percebeu-se que foi alcançado o objetivo de atrair a atenção dos alunos com a metodologia utilizada, contudo, observou-se que a interação da turma ainda era incipiente, talvez por timidez, vergonha ou imaturidade; ou mesmo pelo caráter de novidade, pois era o seu primeiro contato com a Bioestatística e Epidemiologia. Dessa maneira, nas aulas seguintes, foram utilizados novamente os recursos que se mostraram satisfatórios, sendo adaptados e incluídos novos recursos de acordo com os conteúdos específicos de cada aula. A turma foi instigada a participar cada vez mais das discussões e, aos poucos, foi se mostrando mais a vontade e desenvolta para fazer questionamentos, esclarecer dúvidas e tecer comentários ao longo das aulas seguintes.

O professor deve estar sempre atento às potencialidades, necessidades e dificuldades de sua turma. Sendo que é de responsabilidade do docente buscar estratégias de aprendizagem que estimulem os alunos, para que estes se interessem pelos conteúdos abordados. Segundo Jonnaert e Borght ${ }^{14}$, cabe ao professor criar as condições necessárias para auxiliar seus alunos na construção do conhecimento. De acordo com esta visão, o professor precisa ter o entendimento de que ensinar não é simplesmente transferir conhecimento, seu papel 
na prática educativa é provocar e instigar os alunos a pensarem criticamente e a se colocarem como sujeitos de sua própria aprendizagem, atuando como mediador e facilitador da aprendizagem $^{15}$.

Nesse contexto, faz-se necessário registrar a relevância do uso de recursos didáticos complementares às aulas expositivas, que auxiliaram na dinamização das aulas e facilitaram a aproximação dos graduandos com os conteúdos trabalhados. Nesta prática, foram utilizados: estudos dirigidos, correção e discussão de exercícios, demonstrações práticas em sala de aula, paródias musicais, jogo de perguntas e respostas (Quiz Interativo) em grupo e oficina de artigos, que se mostraram eficazes para envolver os alunos no processo de aprendizagem.

Outra estratégia utilizada para facilitar o processo de ensino-aprendizagem dos alunos foi a utilização da aula prática em laboratório, que se constitui como importante recurso metodológico na prática educativa. Através da experimentação, é possível aliar os conteúdos apresentados nas aulas teóricas à prática, e assim, transformar o aluno em sujeito da sua própria aprendizagem, possibilitando a construção da aprendizagem significativa do conhecimento $^{16}$.

No estudo de Silva et $a l^{17}$ sobre a importância e eficácia das aulas práticas na aprendizagem significativa de alunos do ensino médio, observou-se que a turma, na qual foi ministrada a aula prática, apresentou melhor desempenho quando comparada às turmas que receberam outros métodos. Partindo desse pressuposto, realizou-se a aula prática sobre Representação Gráfica e Tabular com o intuito de fixar os conteúdos apresentados na aula teórica e proporcionar uma aprendizagem significativa para o alunado.

A participação e acompanhamento do professor orientador durante as aulas ministradas foram de grande valor, proporcionando apoio nos momentos de insegurança, esclarecendo dúvidas em relação ao conteúdo abordado e auxiliando na interação com a turma, transmitindo confiança e tranquilidade aos docentes aprendizes.

Para além das aulas, o professor orientador esteve presente em todas as etapas do estágio docência, desde a leitura e discussão do plano de ensino do componente curricular, planejamento do cronograma; supervisão e correção dos planos de aula, slides e avaliações elaborados; considerações quanto às metodologias utilizadas; até as discussões e esclarecimentos sobre os conteúdos anteriores a apresentação das aulas. O acompanhamento do professor é fundamental para dar apoio diante dos possíveis desafios e problemas que podem surgir no exercício da prática docente, proporcionando segurança aos estagiários $^{18}$

A participação no processo avaliativo foi uma etapa desafiadora para os mestrandos que elaboraram, aplicaram e corrigiram as provas e os trabalhos escritos, experimentando uma parte da complexidade compreendida nesse processo. A avaliação constitui um elemento ininterrupto do processo de aprendizagem, fornecendo um feedback contínuo para todos os envolvidos ${ }^{19}$. Para Fusari10:50, esta é capaz de "determinar a natureza e a quantidade de mudanças efetuadas no comportamento, em função dos objetivos definidos e das estratégias planejadas".

Alguns eventos foram considerados como obstáculos ao processo de ensino-aprendizagem no estágio, como por exemplo, a greve dos vigilantes e recorrentes paralisações por motivos diversos, que ocorreram ao longo do período e o consequente cancelamento das aulas. Esses fatores podem estimular a evasão escolar, um dos problemas mais frequentes da educação brasileira ${ }^{20}$. Na experiência em tela, no período do estágio ocorreu o cancelamento de matrícula (evasão) de uma estudante. Tais fatores exigem do docente flexibilidade e criatividade para redimensionar seu cronograma, atividades e desenvolver mecanismos para manutenção do interesse e motivação da turma.

Outro ponto importante sobre a atividade de estágio é que esta oportuniza a articulação entre teoria e prática. No desenvolvimento deste tirocínio, foi possível aplicar e refletir sobre os conhecimentos adquiridos nas disciplinas estudadas no curso de mestrado: Epidemiologia, Bioestatística e, especialmente, a disciplina Didática aplicada à Saúde, a qual enfatizou os aspectos referentes à docência universitária, como a profissionalização, saberes e papéis docentes no ensino superior. Longarezi et al. ${ }^{21}$ destacam que é através do diálogo entre a atividade prática e a formação teórica que se fundamenta a formação dos professores.

A experiência da prática pedagógica possibilitou aos mestrandos a troca de experiências, o compartilhamento de dúvidas, desafios, saberes e práticas entre si, com professor responsável pelo componente curricular e com os graduandos, sendo fundamental para o aprendizado, aperfeiçoamento e superação de desafios que permeiam o processo de ensino-aprendizagem. A 
interação com os seus pares e com seus orientadores também se configuram como formas do professor aprender a ensinar, através da ação comunicativa ${ }^{11}$.

O tirocínio docência constituiu-se como uma experiência marcante, à medida que auxiliou no desenvolvimento de habilidades do "saber-fazer" e "saber-ser" docente, contribuindo de modo substancial para a formação dos professores iniciantes, que almejam um desempenho profissional de qualidade no campo da educação superior. O saber docente é um saber plural, construído no exercício da função e na prática profissional, sendo o professor ideal aquele que conhece sua matéria, sua disciplina e seu programa, aquele que possui conhecimentos relativos às ciências da educação e à pedagogia, e que desenvolve um saber prático baseado em sua experiência cotidiana com os alunos ${ }^{22}$.

Não obstante os expressivos ganhos obtidos a partir da experiência do tirocínio docência, é crucial lembrar que a formação do professor é um processo contínuo e deve ser acompanhada pela reflexão constante acerca da sua prática. De acordo com Freire ${ }^{4}$, ensinar é uma responsabilidade que precisa ser trabalhada e desenvolvida. Para tanto, o educador precisa, a cada dia, renovar suas habilidades pedagógicas para atender as necessidades dos seus alunos da melhor maneira. Acredita-se que é por meio do comprometimento e da "paixão" pela profissão e pela educação, que o educador pode assumir, verdadeiramente, o seu papel e se interessar em realmente aprender a ensinar.

\section{Conclusões}

Diante da experiência prática, constatou-se o caráter fundamental do exercício do tirocínio docência para a formação do mestre em saúde coletiva, que além da função de pesquisador, deve desempenhar com aptidão a tarefa de ensino, uma vez que, compete-lhe também a função de professor.

O tirocínio docência tem como função primordial promover uma primeira aproximação dos mestres em formação com o campo de prática profissional, constituindo-se como uma valiosa oportunidade para a vivência da relação professor-aluno, como também, para aprender estratégias (posturas) em sala de aula e apreender técnicas e métodos de ensino.

Através dessa vivência, observou-se que é responsabilidade do docente buscar estratégias de aprendizagem que estimulem os alunos, para que estes se interessem pelos conteúdos abordados. Nessa perspectiva, destaca-se a importância do professor orientador, que diante de sua ampla experiência e qualificação na área da docência e da saúde coletiva, nos conduziu a reflexões sobre o ato de ensinar e os aspectos facilitadores da aprendizagem, ressaltando sempre a necessidade de envolvimento da turma.

Considera-se que a experiência da prática pedagógica proporcionada pelo tirocínio docência foi riquíssima, pois, possibilitou o compartilhamento e a troca de conhecimentos entre os alunos, mestrandos e o professor da disciplina, que contribuíram para o aprendizado, aperfeiçoamento e superação de desafios do processo de ensino-aprendizagem.

O tirocínio docência assume, portanto, um papel de grande relevância na formação do pósgraduando, sendo considerado indispensável nesse processo, visto que, é através deste que o conhecimento teórico se consolida na prática, auxiliando na superação de possíveis dificuldades relacionadas à prática docente, aprimorando a mesma, colaborando significativamente para a formação de um docente do ensino superior de qualidade.

Avalia-se a experiência vivenciada como sendo de grande relevância acadêmica, social e educacional, desse modo, acredita-se que este trabalho pode contribuir para reflexões e discussões acerca do processo de ensinoaprendizagem e da formação do professor para ensino superior.

\section{Referencias}

1. Bianchi ACM, Alvarenga M, Bianchi R. Orientações para o Estágio em Licenciatura. São Paulo: Pioneira Thomson Learning; 2005.

2. Libâneo JC. Conteúdos, formação de competências cognitivas e ensino com pesquisa. In: Pimenta SG, Almeida MI de (Orgs.). Pedagogia universitária: caminhos para a formação de professores. São Paulo: Cortez, 2011; 188-212.

3. Corrêa GT, Ribeiro VMB. A formação pedagógica no ensino superior e o papel da pósgraduação stricto sensu. Educ. Pesqui., São Paulo, 2013; 39(2): 319-334.

4. Freire P. Pedagogia da autonomia: saberes necessários à prática educativa. 34 ed. São Paulo: Paz e Terra, 1996.

5. Joaquim NF et al. Estágio docência: um estudo no programa de Pós-Graduação em administração da Universidade Federal de Lavras. 
Rev. adm. contemp., Curitiba, 2011; 15(6).

6. Soares SR, Cunha MI. Programas de pósgraduação em Educação: lugar de formação da docência universitária? Revista Brasileira de PósGraduação, Brasília, 2010; 7(14):577-604.

7. Chamlian HC. Docência na universidade: professores inovadores na USP. Cadernos de Pesquisa [online], São Paulo, 2003; 118: 41-64.

8. COORDENAÇÃO DE APERFEIÇOAMENTO DE PESSOAL DE NÍVEL SUPERIOR - CAPES. Portaria n.o 76, de 14 de abril de 2010. Disponível em: https://www.ufmg.br/prpg/wpcontent/uploads/2015/03/Portaria-076-CAPESDS.pdf. Acesso 25 jun. 2017.

9. Zaidan S. et al. Pós-Graduação, saberes e formação docente: uma análise das repercussões dos cursos de mestrado e doutorado na prática pedagógica de egressos do Programa de PósGraduação da Faculdade de Educação da UFMG (1977-2006). Educação em Revista, Belo Horizonte, 2011; 27(1):129-160.

10. Fusari JC. O Planejamento do Trabalho Pedagógico: algumas Indagações e Tentativas de Respostas. In: Artigo Série Idéias, São Paulo: FDE, 1998;

(8):44-53.

11. Freire AM. Concepções orientadoras do processo de aprendizagem do ensino nos estágios pedagógicos. Colóquio: modelos e práticas de formação inicial de professores, Faculdade de Psicologia e de Ciências da Educação, Universidade de Lisboa. Lisboa, Portugal, 2001. Disponível em: http://www.educ.fc.ul.pt/recentes/mpfip/pdfs/a freire.pdf. Acesso em: 21 jun. 2017.

12. Joaquim NF, Vilas Boas AA, Carrieri AP. Estágio docente: formação profissional, preparação para o ensino ou docência em caráter precário? Educ. Pesqui., São Paulo, 2013; 39(2):351-365.

13. Piletti C. Didática geral. 23ạ ed. São Paulo: Editora Ática, 2001.

14. Jonnaert $P$, Borght CV. Criar condições para aprender: o modelo sócio-construtivista na formação de professores. Porto Alegre: Artmed, 2002.

15. Bulgraen VC. O papel do professor e sua mediação nos processos de elaboração do conhecimento. Revista Conteúdo, Capivari, 2010; 1(4): 30-38.

16. Souza APA. A Necessidade da Relação Entre Teoria e Prática no Ensino de Ciências Naturais. Revista de Ensino, Educação e Ciências Humanas, 2014; 15.

17. Silva AT et al. Aulas práticas: sua importância e eficácia no ensino de biologia. Revista Univap, 2016; 22(40).
18. Vaz BB, Pessoni LML. As contribuições do estágio curricular supervisionado para a formação docente: espaço de construção dos saberes profissionais. Interdisciplinaridade e currículo: uma construção coletiva. II Congresso de Ensino, Pesquisa e Extensão da UEG. 20 a 22 de outubro de 2015. Local: Campus Pirenópolis. Disponível em: http://www.anais.ueg.br/index.php/cepe/article /viewFile/5654/3421. Acesso: 22 jun. 2017.

19. Castro PAPP, Tucunduva CC, Arns EM. A Importância do planejamento das aulas para organização do trabalho do professor em sua prática docente. Revista Científica de Educação, 2008; 10(10).

20. Silva MJD. As causas da evasão escolar: estudo de caso de uma escola pública de Ensino Fundamental no município de Acará - PA. Revista de Geografia e Interdisciplinaridade, 2016; 2(6).

21. Longarezi AM et al. A unidade teoria e prática no contexto da formação de professores. Revista Profissão Docente, Uberaba, 200; 7(15):15-29.

22. Tardif M. Os professores diante do saber: esboço de uma problemática do saber docente. In: TARDIF, M. Saberes docentes e formação profissional. 12. ed. Petrópolis, RJ: Vozes, 2002; 31-55.

\section{Endereço para Correspondência}

Universidade Estadual de Feira de Santana UEFS

Av. Transnordestina, $s / n$ - Novo Horizonte, Feira de Santana - BA

CEP.: 44036-900

e-mail:ssc.academico@hotmail.com

Recebido em 26/08/2017

Aprovado em 05/02/2018

Publicado em 30/03/2018 